\title{
ESCOLA DE TEMPO INTEGRAL: PROJETO, PROCESSOS E GESTÃO
}

\section{FULL TIME SCHOOL: PROJECT, PROCESSES AND MANAGEMENT}

\author{
Beatriz Gomes Nadal ${ }^{\star}$ \\ Palloma Santos Delgobo
}

\begin{abstract}
RESUMO
A presente pesquisa analisa a política de escola de tempo integral em um município do Estado do Paraná e tem como objetivo identificar concepções, características e dificuldades, bem como contribuir com o debate sobre o tema, por meio do processo de implantação de tal política. Desenvolveu-se em uma abordagem qualitativa e interpretativa com estudo bibliográfico e pesquisa de campo. O estudo bibliográfico apoiou-se em autores cuja produção na área é considerada relevante, como Arroyo (1988), Gadotti (2009) Maurício (2009), Brandalise e Rodrigues (1998), Cavaliere (2007; 2014), Moll (2012), Coelho e Cavaliere (2002) e Antunes e Padilha (2010). A pesquisa de campo foi desenvolvida por meio de questionários, visando coletar dados junto a nove gestores pertencentes às escolas da rede municipal que tinham a política de tempo integral em andamento. Constatou-se que a escola de tempo integral nem sempre está associada à de educação integral e que houve ganhos quanto às condições de trabalho dos professores (hora-atividade) e o cuidado e alimentação das crianças. Há que se avançar em termos de espaço físico, ampliação do quadro de educadores e aperfeiçoamento do trabalho pedagógico face à proposta em tela.
\end{abstract}

Palavras-chave: Educação integral. Escola de tempo integral. Organização escolar. Gestão escolar.

\begin{abstract}
This research addresses the full-time school policy in a city in the State of Paraná, aiming at knowing the process of implementation of such policy in order to identify conceptions, characteristics and difficulties as well as contributing to the debate of this theme. The study was developed through a qualitative and interpretive approach including bibliographic survey and field research. The theoretical background included authors whose production in this area is considered relevant such as Arroyo (1988), Gadotti (2009) Maurício (2009), Brandalise and Rodrigues (1998), Cavaliere (2007; 2014), Moll (2012), Coelho and Cavaliere (2002) and Antunes and Padilha (2010). The field research employed questionnaires with the purpose of obtaining data from 9 managers belonging to the municipal education system in schools where the full time school project had been implemented. The results showed that the full time school is not always associated to full time education, but that there were some gains regarding the teachers' working conditions (planning and preparation time) and children's care and food. There is still room for improvement in the physical space, increase in the number of educators and improvement of the pedagogical work regarding the proposal being investigated
\end{abstract}

Keywords: Full time education. Full time school. School organization. School management.

\footnotetext{
Doutora em Educação e Currículo pela Pontifícia Universidade Católica de São Paulo (PUC-SP).

** Graduada em Pedagogia pela Universidade Estadual de Ponta Grossa (UEPG).
} 


\section{INTRODUÇÃO}

A trajetória da educação pública, laica, gratuita e universal é uma história de negação. Ainda que a conquista da escola seja resultado de lutas, suas finalidades educativas junto às camadas populares nunca foram plenamente atingidas, configurando-se muito mais política compensatória para com as classes menos favorecidas do que projeto de Estado comprometido com tais classes. Isso faz persistir a pressão social por políticas capazes de garantir a democratização da educação não apenas nos termos de seu acesso, mas na aprendizagem para todas as crianças indistintamente.

É nesse cenário que se insere o debate sobre a educação integral e a escola de tempo integral (ETI). A principal característica de tal política é a ampliação do tempo de permanência dos alunos na escola visando sua formação integral, ou seja, a formação plena das crianças, permitindo a elas que se constituam sujeitos autônomos, conscientes e críticos.

Além da instrução escolar, ela estaria implicada na educação física e moral, na educação para a cidadania, na educação para a sociedade da informação e da comunicação, na difusão cultural, na socialização primária no caso das crianças pequenas e, no caso dos jovens, na formação para o trabalho. (CAVALIERE, 2014, p. 1207)

O presente trabalho aborda, então, a política de escola de tempo integral no município de Ponta Grossa, no Paraná, questionando as concepções que nortearam tal processo, as características que assumiu, bem como as dificuldades sentidas pelas escolas tendo em vista sua aplicação.

A investigação mostrou que a escola de tempo integral nem sempre está associada à educação integral. A proposta contou com ganhos quanto às condições de trabalho dos professores (em especial sua hora-atividade), ao cuidado e à alimentação das crianças. Há necessidades de avanços em termos de espaço físico, ampliação do quadro de educadores e aperfeiçoamento do trabalho pedagógico face à proposta em tela. A ausência de formação e reflexão foi elemento dificultador para que a escola de tempo integral se caracterizasse, no momento de sua implantação, mais como processo formal de reforma e menos como proposta pedagógica encampada reflexiva e criticamente pelas escolas.

\section{EDUCAÇÃO INTEGRAL - TEMPO INTEGRAL}

A busca da melhoria da qualidade tem remetido ao debate sobre a formação integral da criança: uma educação que seja pública, laica e democrática, visando o desenvolvimento do aluno em suas múltiplas dimensões. Uma educação que reconheça o ser humano em sua totalidade e lhe garanta, de fato, a integralidade:

Quando nos referimos à Educação Integral, estamos falando de uma educação que trabalha pelo atendimento e pelo desenvolvimento integral do educando nos aspectos biológicos, psicológicos, cognitivos, comportamentais, afetivos, relacionais, valorativos, sexuais, éticos, estéticos, criativos, artísticos, ambientais, políticos, tecnológicos e profissionais. Educar integralmente o cidadão e a cidadã significa, pois, prepará-los para uma vida saudável e para a convivência humanizada, solidária e pacífica. (ANTUNES; PADILHA, 2010, p.17)

A educação integral associa-se ao tempo integral na escola, ainda que deva ser buscada a despeito do tempo escolar existente. Mesmo que distintas, educação e tempo se complementam face à busca da qualidade da formação escolar.

Cavaliere (2007) identificou quatro concepções de escola de tempo integral: assistencialista, autoritária, democrática e multissetorial. A visão assistencialista é a predominante e busca suprir as mazelas da sociedade, prevendo que as crianças sejam "atendidas" em decorrência de novos arranjos sociais, econômicos, familiares ou do mundo. Na autoritária, a escola é entendida como "uma espécie de instituição de prevenção ao crime". A concepção multissetorial volta-se para a educação não formal, compreendendo que o currículo escolar seria desenvolvido na escola e que um estudo diferenciado seria ofertado em outros espaços, como igrejas, organizações e associações, não apenas por professores, mas por outros educadores. Segundo a autora, esta concepção não favorece a educação integral do homem por não contemplar uma diretriz a ser seguida ou uma intencionalidade em relação aos saberes científicos.

Em uma concepção democrática de escola de tempo integral, toda a educação formal é realizada no próprio espaço escolar, articulando um currículo comum a outros conhecimentos e atividades que 
podem incluir esportes, acompanhamento pedagógico, práticas corporais e lúdicas, projetos ambientais, de natureza estética, entre outros relacionados à realidade de cada escola.

A necessidade de ampliação da jornada escolar dos alunos é justificada por Leite com base em dois argumentos: a "busca pela melhoria na qualidade do ensino, por meio de uma formação mais completa, e a proteção à criança em situação de vulnerabilidade social" (2012, p.81).

Embora educação integral e tempo integral sejam termos distintos entre si, eles se complementam, pois a formação está intimamente relacionada ao tempo de permanência do aluno na escola. O termo "escolas integrais" refere-se à função educativa da escola, e não à extensão do período diário de escolaridade.

Assim, o conceito de escola de tempo integral está relacionado ao tempo de permanência do aluno na escola, como apontam Brandalise e Rodrigues (1998):

[...] o conceito de horário integral discute a possibilidade de manter o aluno mais tempo dentro da escola ou em atividades na comunidade escolar, no contraturno, mas melhor acompanhado, melhor alimentado e melhor cuidado, procurando estimulá-lo a realizar outras aprendizagens fundamentais para a sua formação plena (integral) como cidadão de direitos. (2010, p. 20)

A escola de tempo de tempo integral está associada ao crescimento dos alunos e da comunidade escolar, sendo um processo de extrema importância essencialmente para as classes populares, dada a exclusão educativa a que foram submetidas historicamente, configurando-se uma importante política de democratização educacional.

\section{PROPOSTA DE TEMPO INTEGRAL NO MUNICÍPIO DE PONTA GROSSA (PR)}

O tempo integral se caracteriza pela oferta de um ensino ampliado que passe de quatro horas diárias para, no mínimo, sete. É uma política educacional com potencial frente à melhoria da qualidade, pois pode estar associada ao desenvolvimento da aprendizagem, ao cuidado social das crianças e à própria democratização da educação:

O direito à educação traduz-se hoje, no Brasil, como o direito a um padrão de qualidade educacional, em que pesem as dificuldades em estabelecer-se um consenso sobre a própria noção de qualidade, mesmo quando se afirma a ideia de uma qualidade "socialmente referida". Ainda que pouco precisa, a expectativa pela qualidade educacional está, mais do que nunca, presente na sociedade brasileira que não apenas percebe a diferença qualitativa entre as escolas existentes - diferença rigorosamente espelhada na hierarquia social - mas também se pergunta sobre o que a escola pode e deve ensinar e quais as suas responsabilidades específicas. É em função dessa expectativa que a escola de tempo integral aparece como elemento para um possível avanço em direção à referida qualidade, a depender do sentido e das funções que a ela se venha atribuir. (CAVALIERE, 2014, p. 1206)

Dadas suas potencialidades, observa-se que o tempo integral passou a ser contemplado nas políticas educacionais, tendo as redes públicas se lançado a tais experiências pedagógicas. Em Ponta Grossa, no Paraná, a Secretaria Municipal de Educação implantou, em 2014, a nova modalidade inicialmente em nove escolas, prevendo a progressiva ampliação desse número.

O município de Ponta Grossa localiza-se no segundo Planalto do Paraná, com 348.043 habitantes, segundo dados do IBGE (Instituto Brasileiro de Geografia e Estatística) de 2018. É uma cidade que se destaca por sua ligação ferroviária, pontos turísticos, universidades, indústrias, comércio, dentre outras atividades decorrentes de sua origem colonizadora no tropeirismo.

Trata-se de um município urbano, com índice de urbanização de cerca de 97\%. Lidera os municípios dos Campos Gerais com seu parque industrial (maior do interior do estado) e possui um alto IDH (0.763). A potencialidade da cidade também pode ser vista pelo IDH municipal - IDHM -, que contempla educação, longevidade e renda, sendo a longevidade o primeiro fator a impactar o índice; a renda, o segundo; e a educação, o terceiro. Dentre os três, a educação foi o fator que mais cresceu em termos absolutos com base no cálculo de percentual de adultos que concluíram o Ensino Fundamental e de crianças e jovens frequentando e concluindo o Ensino Fundamental e Médio (BUENO, 2017).

No que tange à sua rede de atendimento público dos anos iniciais, a cidade conta atualmente com 84 escolas municipais de Ensino Fundamental, do 1. ${ }^{\circ}$ ao 
5. ${ }^{\circ}$ ano, atendendo 22.016 crianças. São 79 escolas na zona urbana e cinco na zona rural. Os anos finais são ofertados em 43 escolas pertencentes à rede estadual de ensino.

Dentre as escolas municipais, quando da implantação em 2014, 18 eram de tempo integral, abrangendo, em média, 4.023 crianças em tempo ampliado. Essas 18 estavam divididas entre o Programa Mais Educação ${ }^{1}$ (nove escolas) e o projeto de tempo integral da própria Secretaria de Educação (nove escolas), organizadas por meio de projeto pedagógico e financiamento municipais.

Para a implantação de sua política de escola de tempo integral, a Secretaria (SME) utilizou como critérios de seleção o perfil socioeconômico das comunidades atendidas pelas escolas, o nível de aprendizagem apresentado e a existência de condições organizacionais. Destaque-se que apenas uma dentre as nove escolas optou autonomamente pela proposta, tendo sido as demais selecionadas pela Secretaria.

A Secretaria não formulou um documento norteador da proposta da SME para a implantação do tempo integral, de modo que, na ausência de tal diretriz, buscaram-se informações diretamente com a secretária de educação, o que justificou a realização de entrevista.

O conjunto das informações permitiu perceber a preocupação da SME em iniciar o processo de ampliação do tempo escolar nas escolas da rede municipal tanto em decorrência da concepção de educação contemplada na proposta de governo como do movimento nacional em defesa desta ampliação, em especial a meta do Plano Nacional de Educação de implantação do regime de tempo integral em pelo menos $50 \%$ das escolas brasileiras. Assim, a SME propôs a educação integral como desenvolvimento do aluno em diferentes dimensões:

Bem, [...] tanto faz a escola ser de tempo parcial ou de tempo ampliado, ela tem que ter uma educação integral, desenvolver o sujeito em todas as suas dimensões, não importa o tempo da escola. Educação Integral é a forma que a gente tem que organizar todo o nosso trabalho pedagógico, desenvolver a criança em todas as dimensões. Então educação integral não tem nada a ver com escola de tempo

\footnotetext{
${ }^{1}$ O Programa Federal Mais Educação induz a educação em tempo integral como política pública, repassando recursos para garantir a ampliação de tempos, espaços e oportunidades educativas.
}

ampliado, ela pode acontecer tanto no tempo parcial quanto no tempo ampliado. (SECRETÁRIA DE EDUCAÇÃO)

Ao implantar a política de tempo integral, a SME parece ter buscado garantir o direito legal do cidadão à melhoria da qualidade da educação, principalmente em questões básicas de letramento, e das condições de trabalho dos professores.

Principalmente melhorar a qualidade da nossa educação. Nós estamos com crianças saindo do $5 .^{\circ}$ ano, indo para o $6 .^{\circ}$ ano sem saber ler, sem saber escrever, sem saber o básico de matemática. Então a primeira questão é essa, a qualidade de ensino.

Mas a escola de tempo integral também melhora a qualidade das condições de trabalho dos professores, porque o professor [...] está tendo 13 horas de hora atividade, quer dizer, se ele tem um contrato de 40 horas ele tem 27 de horas de trabalho docente e 13 horas de planejamento e organização da escola e tudo mais. Então melhora a condição de trabalho do professor, ela ajuda tanto o professor quanto os alunos. (SECRETÁRIA DE EDUCAÇÃO)

Em relação à organização, a primeira mudança visível na escola de tempo integral foi o tempo. Se, antes, as crianças da rede municipal permaneciam nas escolas por 4 horas diárias, elas passaram a ter 7 horas de atividades curriculares e 2 horas para descanso, divididas entre higiene e alimentação, em uma escola de 9 horas diárias com horário de entrada de 07h45 e de saída, 16h45. Nas sextas-feiras, as atividades discentes encerravam-se às $11 \mathrm{~h} 45$ para que o período da tarde fosse destinado ao planejamento dos professores.

Vale ressaltar que, na escola de tempo parcial, as inúmeras atividades e atribuições assumidas pelas escolas tornaram o tempo insuficiente, tendo as tarefas de casa muitas vezes assumido a função de delegar aos pais a responsabilidade de complementar e compensar o trabalho escolar:

Os exercícios em sala são quase sempre insuficientes, as idas à biblioteca (quando há biblioteca) não são mais do que visitas rápidas e intermitentes, os trabalhos em laboratório jamais conseguem ser a contrapartida prática do trabalho teórico. Diante desses limites, os professores delegam essa parte decisiva da formação para as tarefas-extraclasse. [...] O tempo integral, como pode ser constatado nas diversas experiências levadas a efeito mundo afora 
e também no Brasil, permite organizar as atividades escolares segundo métodos adequados do ensinar e do aprender. (GIOLO, 2012, p. 98-99)

Para organizar as escolas em tempo integral, em especial, para pensar as práticas pedagógicas do novo período acrescido ao tempo escolar, a SME se referenciou nos eixos norteadores do programa Mais Educação do Governo Federal, além de ter proposto eixos próprios. A proposta apresentou seis eixos norteadores da organização pedagógica do tempo escolar: ludicidade; corpo e movimento; acompanhamento pedagógico; homem, meio ambiente e sustentabilidade; cidadania e diversidade cultural e linguagens.

Com exceção do acompanhamento pedagógico (que é um eixo obrigatório), os demais foram selecionados por cada escola com base em sua proposta pedagógica e se desenvolveram por meio de diferentes projetos e atividades no período contrário ao do trabalho com os conteúdos do núcleo curricular comum. Desse modo, em um período letivo, os alunos trabalhavam com atividades pedagógicas relativas aos eixos e, no outro, dedicavam-se exclusivamente ao estudo do núcleo comum, conteúdos curriculares que já constituíam as diretrizes do Ensino Fundamental.

A maioria das escolas organizou-se para realizar, no período da manhã, atividades relativas aos eixos norteadores (projetos pedagógicos), aulas de Educação Física e de Música, e, no da tarde, exclusivamente atividades curriculares do núcleo comum, sem "quebra de horário". Tal organização foi pensada visando à melhoria da qualidade de educação no município, pois muitos alunos estariam concluindo o Ensino Fundamental I com deficiências na aprendizagem.

Em relação à organização dos espaços, cinco das nove escolas ofereciam também Educação Infantil além do Ensino Fundamental, de maneira que três dessas são complexos educacionais, com espaço físico e proposta arquitetônica diferenciados. De modo geral, a implantação do período integral não foi acompanhada de ampliação de espaço físico, realizandose apenas sua reorganização, a fim de adaptá-los da melhor forma possível. Segundo a SME, nem sempre a questão física é a maior garantia de uma escola de qualidade, pois, em primeiro lugar, há de existir uma concepção de tempo integral por parte de todos os profissionais da escola:
[...] pegamos todas as diretoras e pedagogas e fomos visitar as escolas de tempo integral. Uma escola com estrutura, grande e tudo mais, e uma escola sem estrutura. Elas foram visitar as escolas para desconstruir aquele conceito de que precisa ter um monte de estrutura para ter uma escola de tempo integral. Não precisa, porque nós temos umas escolas com pouca estrutura funcionando muito bem e escola com estrutura enorme que não funciona nada, não funciona absolutamente nada. A escola de tempo integral passa pela concepção do grupo de gestão que precisa entender o projeto, saber organizar os espaços e trabalhar. Ela não tem outra saída. (SECRETÁRIA DE EDUCAÇÃO)

Outro fator importante na ETI é seu financiamento, pois se trata de uma proposta de alto custo, que requer investimentos. Na proposta da SME, não houve mudança na destinação de verbas às unidades escolares, pois considerou-se que o número de alunos não se modificou, ainda que permanecessem na escola pelo dobro do tempo. A própria Secretária reconhece o fato de ser uma escola muito cara, ressaltando os custos com profissionais:

Em relação ao financiamento não teve mudança, porque o número de alunos continuou o mesmo. Houve aumento de funcionários para limpeza e para fazer a alimentação.

O número de alunos é o mesmo, então passa o mesmo recurso. O valor é per capta. O que a escola tem a mais? A escola tem a mais: mais suporte, em relação à mais professor, mais merendeira, mais servente, mas o que a gente passa pelo Pro-educação é pelo porte da escola e pelo número de alunos, não tem diferença.

Se ela tinha 300 alunos, 150 de manhã e 150 tarde, ela tem 300 do mesmo jeito, então ela recebe pelo valor de alunos. Esse não é o problema, não é a questão financeira, ela fica cara porque eu preciso de mais pessoas, eu preciso nesta escola de mais pessoas. Não é esse o problema, o problema na escola de tempo integral é a concepção, principalmente da equipe de gestão. (SECRETÁRIA DE EDUCAÇÃO, 2014)

A manutenção do financiamento em detrimento do aumento do tempo escolar certamente foi fator precarizador da proposta, destituindo as concepções pedagógicas da materialidade que sua implementação requer. 
Se, em termos de espaço físico e destinação de recursos financeiros, não houve grandes mudanças, o mesmo não ocorreu na questão do quadro de profissionais, pois, embora com a ampliação do número de educadores - e com a maioria dos professores atuando em regime de 40 horas semanais -, a falta destes ainda permaneceu como um dos problemas a serem sanados.

Em contrapartida, o tempo ampliado favoreceu o desenvolvimento profissional dos professores e a qualidade de seu trabalho, em especial daqueles que atuam 40 horas nas unidades escolares, pois, além do momento coletivo de planejamento, a maioria dos professores passou a contar com hora-atividade durante a semana, totalizando 13 horas semanais para formação, preparo e trabalho coletivo.

Em relação à preparação das escolas para a implantação da proposta do tempo integral, houve indicação, por parte da secretaria, de espaços para que equipes gestoras e pedagógicas estudassem o tema:

Nós trabalhamos [...] discutindo a escola de tempo integral, o ano todo, tanto é que uma escola quis e teve gente que teve muito medo. E hoje é diferente. Pelas visitas que a gente está fazendo, tem um monte de professoras e diretoras de escola vindo aqui e se colocando à disposição para a escola ser de tempo integral, uma porção delas, pois elas viram como melhorou a comunidade, a escola, e como é melhor para elas lidarem com a escola. Aquele menino dela que ela pegava meio período, aquele menino circula na escola dela o dia inteiro, ela está muito boa nessa parte. A secretaria preparou, discutimos o tempo todo, tanto a parte histórica, começando desde Anísio Teixeira, toda a experiência do Brizola no Rio de Janeiro, depois toda a concepção dos CAICs e dos CIACs que depois se transformou em CAIC e nós fomos discutindo estas concepções todas, desde a parte histórica como a parte teórica. (SECRETÁRIA DE EDUCAÇÃO)

Todavia, a formação inicialmente propiciada parece ter sido insuficiente frente à necessidade de desenvolvimento, por parte das escolas, de uma concepção de educação integral e da organização de práticas pedagógicas em escolas de tempo integral:

[...] um erro que cometeu é que em escolas cujos professores tinham 40 horas, conforme a concepção da gestão, ela pôs o professor o dia inteiro responsável pela classe, isso é horrível, é um erro, pela mesma turma o dia inteiro. Isso é horrível para a criança e para o professor mas se a escola tem au- tonomia para organizar então há falta de compreensão da própria organização da escola. Ela fez isso porque para o diretor e para a pedagoga é tranquilo porque para ele qual é o problema que todos eles têm? Eu tenho relatório aqui das escolas de tempo integral e é a hora do almoço, porque eles não estão acostumados com crianças circularem pela escola sem a tutela de um professor. Então, se ele pega um professor que é de 40 horas e essa professora vai ficar o dia inteiro cuidando dessa criança, desse grupo, a escola fica tranquila, mas a escola de tempo integral não pode funcionar assim, ainda que exista isso. (SECRETÁRIA).

Diante da complexidade da implantação de uma política de tal natureza e considerando sua garantia em lei, a formação continuada para as escolas e seus profissionais passou a acontecer paralelamente ao processo, por meio de seminários, grupos de estudo e visitas das equipes gestoras às escolas parceiras, visando possibilitar melhor integração e enriquecimento da proposta, a fim de que seja continuamente aprimorada.

Observando a exposição da proposta das escolas de tempo integral enquanto proposta política, fica evidente a falta de planejamento e preparação das unidades escolares para a implementação, bem como o caráter pragmático e adaptado à que se submeteram, pois se entende como indissociável a efetivação de uma política das condições materiais por ela requeridas.

\section{ESCOLAS DE TEMPO INTEGRAL EM PONTA GROSSA: DIFICULDADES E CONQUISTAS NO PROCESSO DE IMPLANTAÇÃO}

Em vista da implantação do projeto de escolas em tempo integral em um município paranaense, nos motivamos a realizar uma pesquisa que objetivou conhecer o processo de implantação de tal política a fim de identificar, do ponto de vista das equipes de gestão (diretores), concepções, características e dificuldades, bem como contribuir com o debate sobre o tema. A pesquisa desenvolveu-se por meio de uma abordagem qualitativa, do tipo interpretativa, e contemplou estudo bibliográfico e pesquisa de campo.

A pesquisa interpretativa "se preocupa fundamentalmente em indagar o significado dos fenômenos 
educativos na complexidade da realidade natural na qual se produzem." (GÓMEZ, 1998, p. 102). O estudo bibliográfico foi utilizado com vistas a permitir uma aproximação ao campo teórico da temática. Para tanto, apoiamo-nos em autores cuja produção na área é considerada relevante, como Teixeira (1976; 1967; 1971), Freire (1982), Arroyo (2012), Gadotti (2009), Maurício (2009), Brandalise e Rodrigues (1998), Cavaliere (2007, 2014), Moll (2012), Coelho e Cavaliere (2002) e Antunes e Padilha (2010).

Face aos objetivos pretendidos, a pesquisa de campo foi desenvolvida por meio de questionários, visando coletar dados junto aos gestores pertencentes às escolas da rede pública. Assim, foram selecionados os nove gestores atuantes na rede municipal que tinham a política de tempo integral em andamento. Para preservar a identidade dos respondentes e das escolas, estes foram designados como A, B, C, D, E, F, G, H e I.

A opção pelo uso de questionário se deu em virtude de sua rapidez para a coleta de dados junto ao número de participantes pretendidos (9). Tendo em vista os objetivos da pesquisa, o questionário foi estruturado com questões fechadas e abertas, permitindo coletar informações objetivas sobre as escolas, como também percepções, opiniões e concepções dos diretores a respeito do processo de implantação e funcionamento da escola de tempo integral.

Realizou-se, ainda, uma entrevista semiestruturada com a Secretária Municipal de Educação a fim de coletar informações que auxiliassem na apresentação e descrição da proposta. Essa entrevista foi fundamental na medida em que o processo de implantação da política se deu sem que houvesse a formulação de um documento político capaz de sustentar a análise. A entrevista foi gravada por um gravador manual e integralmente transcrita.

Os dados coletados, organizados conforme semelhanças entre as respostas para resultar em uma análise teórica, foram agrupados, então, nos seguintes eixos: Concepção de educação integral e de tempo integral; Escola de tempo integral: inovação?; Escola de tempo integral: reestruturação do tempo-espaço e equipes de trabalho; e $\mathrm{O}$ tempo integral e as práticas pedagógicas face à educação integral.

\section{CONCEPÇÃO DE ESCOLA DE TEMPO INTEGRAL (ETI)}

A escola de tempo integral caracteriza-se principalmente pela oferta de ensino em tempo ampliado face ao período anteriormente existente, que era de 4 horas. Pretende-se que a criança fique na escola por um período aproximado de 7 horas diárias, para poder realizar mais atividades e enriquecer sua aprendizagem, melhorando, assim, a qualidade do ensino.

O tempo integral, com pode ser constatado nas diversas experiências levadas a efeito mundo afora $\mathrm{e}$ também no Brasil, permite organizar as atividades escolares segundo métodos adequados do ensinar e do aprender. O contexto escolar, especialmente o destinado às classes populares, tem de ser organizado e forte o suficiente para provocar no aluno uma verdadeira ruptura entre os esquemas mentais ditados por uma cultura prática, oral e visual, em favor de uma cultura escrita e intelectualizada. (GIOLO, 2012, p.99)

Ainda que a ETI tenha como primeira característica o trabalho em turno ampliado e a consequente reorganização da escola em função deste, entendese ser fundamental que tal alteração estrutural esteja pautada em uma concepção educativa.

A coleta de dados junto aos diretores permitiu observar que, para a grande maioria (7) deles, a ETI é aquela em que há apenas ampliação do tempo escolar e diversificação das atividades pedagógicas ofertadas em relação ao trabalho comumente desenvolvido, tal como pode-se observar nas seguintes respostas:

É uma escola que além de atender as necessidades cognitivas dos alunos, possibilita mudanças na vida das crianças que precisam ficar na escola o tempo 'integral' para suprir algumas necessidades que a família não consegue. (Diretor B)

É uma escola que amplia a jornada escolar de 20 horas semanais, para 36 horas semanais e com isso promove a ampliação de oportunidades educativas e enriquece o aprendizado do aluno. (Diretor I)

Percebeu-se que muitas diretoras revelaram uma visão restrita e pragmática em relação a uma escola de tempo integral, sem estabelecer a relação que existe com a educação integral. Conforme aponta Gadotti (2009), mesmo que a escola não seja de tempo ampliado, ela precisa ter uma formação voltada à 
formação do sujeito integral, e assim deve ser, consequentemente, na ETI.

Contudo, dois diretores apresentaram uma concepção ampliada de tempo integral, associando-o ao desenvolvimento integral do aluno, relacionando essa forma de organização escolar à sua possibilidade formativa (de desenvolvimento de potencialidades)

É uma proposta que visa atender o desenvolvimento integral do aluno através de projetos que abrangem diversas áreas e também amplia o tempo de permanência do aluno na escola trazendo inúmeros benefícios. (Diretor F)

A Escola de Tempo Integral (ETI) do município de Ponta Grossa é uma política que amplia o tempo de permanência da criança na escola com atividades complementares que envolvam arte, tecnologias, esportes, ludicidade. A Escola de Tempo Integral amplia as oportunidades educativas que favorecem o desenvolvimento integral dos alunos. (Diretor $\mathrm{H}$ )

A visão de caráter mais restrito e utilitarista sobre a ETI também se manifestou quando os diretores argumentaram sobre a importância dessa política para as escolas:

[...] alguns alunos da nossa comunidade estão em situação de risco e os pais, precisam trabalhar, sendo assim a escola de tempo integral contribui, para melhorar a condição sócia - econômica das famílias e das crianças. (Diretor B)

[...] a ampliação do tempo na escola atende as necessidades dos educandos na comunidade que hoje tem atividades na escola, aprendem, se alimentam adequadamente e estão livres das ruas. (Diretor D) [...] tudo que ela favorece é positivo a ampliação do tempo da criança na escola também retira a criança do risco social. (Diretora $\mathrm{G}$ )

As respostas evidenciaram a prevalência do sentido de escola de tempo integral como prática de cuidado, pois sete dos respondentes justificaram-na em virtude de seu caráter assistencialista, haja vista a vulnerabilidade das crianças, a má alimentação que desfrutam devido à condição socioeconômica das famílias e a necessidade de trabalho dos pais. As respostas convergem, assim, para as concepções assistencialista e autoritária sistematizadas por Cavaliere (2007).

Observamos a importância de que o tempo integral na escola esteja sustentado em uma concepção de educação integral de maneira que os objetivos pedagógicos sejam realmente alcançados. Ao contrário, a escola corre o risco de se transformar em agência de mascaramento de problemas sociais, assumindo funções que não lhe pertencem.

\section{ESCOLA DE TEMPO INTEGRAL: INOVAÇÃO?}

Refletindo anseios populares, elaborações do campo acadêmico ou mesmo em resposta às necessidades concretas das escolas, projetos de mudança são continuamente propostos pelos governos em direção ao que acreditam ser melhoria da qualidade da educação. Normalmente, tais mudanças configuramse como reformas, propostas impostas de cima para baixo, seguindo uma hierarquia vertical de imposição de ordens em que o maior (nível macro $=$ Estado) as formula e impõe às minorias, tidas aqui como as secretarias municipais ou as escolas propriamente ditas.

As reformas verticais, concebidas de cima para baixo, assim como os modelos de mudanças baseados no saber dos especialistas e nas prescrições legais, reproduzem na escola a divisão técnica e social do trabalho entre as pessoas que pensam e planejam e as que se limitam a receber instruções e executá-las mecânica e passivamente. (CARBONELL, 2002, p.27)

Diferentemente das reformas, as inovações são mudanças do tipo "de baixo para cima", caracterizando-se pela transformação horizontalizada (partindo da realidade existente) da essência das práticas pedagógicas, e não apenas por alterações pontuais. Inovar, de acordo com Carbonell (2002, p. 19), consiste em "um conjunto de intervenções, decisões, processos, com certo grau de intencionalidade e sistematizações, que tratam de modificar atitudes, ideias, culturas, conteúdos, modelos e práticas pedagógicas".

Todavia, é importante observar que, em alguns momentos, as reformas se fazem necessárias, haja vista o papel do Estado na proposição de políticas com vistas justamente ao enfrentamento dos problemas e das questões sob sua responsabilidade. Nesse caso, é importante que as reformas sejam estruturadas com base nos problemas da prática. Ainda que complexo, pensar a reforma sob esse viés acarretará maior aceitação e chances de que sejam mais assertivas.

Investigando os diretores escolares sobre o processo de implantação das ETI, percebemos que sete das nove escolas implantaram esta proposta por 
meio de uma determinação da SME como reforma no âmbito de um programa de governo (uma escola não soube responder). Nesses casos, o fator preponderante na seleção da escola pelo sistema foi o baixo nível socioeconômico dos alunos atendidos e o baixo IDEB (Índice de Desenvolvimento da Educação Básica)

Foi a secretaria de educação que, vendo as questões da comunidade e o perfil da Escola, escolheu essa modalidade de ensino para nossa escola. (Diretor C) [...] é uma política do governo e a Secretária de Educação, de alguma forma teria que iniciar a implementação dessa escola de tempo integral. Sendo a nossa, uma escola grande, com muitos alunos, atendendo uma comunidade bastante complicada com vários aspectos, penso que isso pesou no momento da escolha das escolas que estariam funcionando em tempo integral a partir de 2014. (Diretor E)

O governo implantou o tempo integral em nossa escola devido à quantidade grande de Bolsas Família de nossos alunos, por ser uma comunidade carente. (Diretor I)

Somente uma escola solicitou à SME a implantação da nova política:

Espaço físico. Todos os funcionários "abraçaram a causa". (Diretor G)

Analisando as respostas, somos levados a crer que a implantação das ETI teve caráter de reforma, pois, como assinalaram os respondentes, o tempo foi ampliado precipuamente por determinação vinda da secretaria de educação. Associando tais respostas às anteriores, que trataram da importância do tempo integral para as escolas, pudemos inferir que a baixa relação entre tempo integral e educação integral estabelecida pelos diretores reafirma a hipótese do fenômeno da reforma, pois, guindadas à condição de integral pela SME, as escolas pareceram ainda não ter elaborado sua própria concepção de ETI, pelo que a restringiram a de escola que cuida e protege.

Um elemento importante para o impulsionamento das inovações é a formação dos professores, dado o caráter de desenvolvimento a que está associada. Em relação ao processo de formação realizado com o objetivo de preparar as escolas para a implantação da política da tempo integral, houve divergência entre os respondentes:
Sim. Tivemos formação continuada, reuniões explicativas da proposta do projeto pela Secretaria Municipal de Educação. (Diretor A)

Tivemos apenas uma reunião geral, falando de horários, da organização e o restante estamos aprendendo na prática, testando o que da certo, o que não, ainda precisamos melhorar muito. [...] (Diretor B)

Estão ocorrendo formações gradativas. (Diretor C) Sim, através de reuniões, formações debates, discussões, visitas. (Diretor D)

Pouco; a decisão foi rápida e estamos em processo de capacitação junto com a implantação (simultânea). (Diretor F)

Ainda que existente, observa-se que a formação que sustentou a reforma parece ter assumido um caráter mais assistemático, estruturando-se em reuniões de trabalho e envolvendo essencialmente a direção. Todavia, os processos que envolvem a instituição escolar em torno da mudança devem se voltar à comunidade educativa como um todo, a fim de que os envolvidos compreendam de fato sua importância, seus objetivos e se sintam parte dessa organização, tendo maior autonomia para o desenvolvimento da proposta.

Uma reforma implantada sem formação adequada pode enfrentar, em sua operacionalização, medos, resistências, incompreensões e dificuldades, com risco de fracasso. Dessa forma, em relação à aceitação da proposta de tempo integral pela comunidade escolar, vimos que cinco dos nove respondentes revelaram a existência de dificuldades ou resistência nas escolas:

É um processo de adaptação. Tivemos um pouco de dificuldade no início para estabelecer um cronograma de atividades, mas agora incorporou-se à rotina da escola. (Diretor A)

Os professores apresentam resistência à escola de tempo integral, por causa da falta de profissionais especializados e mesmo de regentes de turma e por não terem capacitação adequada para trabalhar projetos mais atrativos para os alunos (dança, capoeira, violão...). Eles não sabem trabalhar com projetos que despertem a atenção dos alunos, fica tudo muito repetitivo. (Diretor B)

Temos trabalhado em formação com os professores principalmente, que é preciso conceber essa escola de uma forma diferente. Para uns está sendo mais fácil, para outros, já nem tanto assim. A disposição do professor para trabalhar numa ETI, difere de um para o outro. (Diretor E) 
Após um pouco de resistência do corpo docente, agora todos estão bem adaptados ao cotidiano da ETI. (Diretor H)

No início houve um certo medo por parte de todos, mas agora todos já abraçaram a causa e gostam do novo sistema. (Diretor I)

Nas outras quatro respostas, os pesquisados relataram aceitação, mas não revelaram se isso está associado à capacidade para o trabalho com a proposta.

Todas estão empenhados para o sucesso da proposta. (Diretor C)

Foi muito boa, não perdemos nenhum funcionário, todos permaneceram na escola e abraçaram a causa. O nível de contentamento está muito bom. (Diretor F) Como já citei anteriormente, os funcionários aceitaram desde o início. (Diretor G)

O diferencial em nossa Escola é que os professores e funcionários escolheram a Escola de tempo Integral, abraçaram a causa e fazem tudo para dar certo. (Diretor D)

$\mathrm{O}$ que se manifestou nas respostas foi o fato de que parece ter ocorrido uma reforma vertical, pois as formações foram escassas e muitos dos envolvidos, principalmente os professores, resistiram, tiveram medo e se adaptaram à política que lhes estava sendo imposta.

Seria necessário haver um processo de formação contínua organizado não apenas pela secretaria de educação para as equipes de gestão das escolas - diretores e pedagogos -, mas também de formação nas próprias escolas com a finalidade de identificar e compreender os problemas oriundos do processo de implantação, fazendo decorrer propostas.

Dentro desta perspectiva sistêmica, também se devem integrar os discursos teóricos com as práticas escolas e, ainda, o pensamento dos especialistas com o pensamento construído pelos professores a partir do seu trabalho cotidiano na classe. Contudo, sabe-se que a mudança é um longo processo: que a prática modifica-se antes que as ideias; e que é preciso pensar globalmente, mas atuar localmente; isto é passo a passo. (CARBONELL, 2002, p.24)

Também as famílias precisam compreender a natureza e o propósito das mudanças em curso como condição para que os objetivos da proposta se efetivem. Em relação à percepção da política da escola de tempo integral pela comunidade escolar, os diretores consideraram que a proposta teve uma boa recepção, ainda que, entre as famílias, tenham sido identificadas dificuldades:

Eles adoraram e colaboram com o que é necessário. Basta adaptarem-se com o horário. (Diretor C)

No início foi difícil, alguns pais não entenderam a proposta. Hoje, após questionário enviado, a maioria apoia e aceita, percebe a mudança no filho, comportamento, hábitos alimentares, postura, aprendizagem. (Diretor D)

Não tivemos nenhum problema com a comunidade, pelo contrário, outras vilas/ bairros vêm solicitar vagas em nossa escola por ser integral. Os alunos estão bem acostumados, no entanto no início ficavam cansados, muitos chegavam a dormir. (Diretor $\mathrm{G}$ )

A comunidade aceitou de forma positiva a propostas, tendo em vista a dificuldade de atividades de contraturno na região. (Diretor $\mathrm{H}$ )

Os pais e os alunos aceitaram bem a proposta. Já ouvimos muitos elogios de pais e relatos de como as crianças gostam de estar na escola. (Diretor I)

Acredita-se que tudo o que é voltado à melhoria da qualidade de ensino dos alunos será bem aceito pela comunidade escolar. No caso do tempo escolar integral, as falas parecem sugerir que o caráter social da proposta pode ter sido um fator motivador, já que a nova configuração da sociedade impõe a eles o trabalho externo sem, necessariamente, criar instituições nas quais possam deixar seus filhos. Se nossa hipótese estiver correta, ter-se-á, mais uma vez, a concepção assistencialista de educação integral apontada por Caveliere (2009) e a formação dos alunos realmente terá abrangido, além do ensinar/ educar, a função do cuidar.

Um instrumento importante no processo de definição da concepção de educação, de educação integral e de escola de tempo integral é o projeto político pedagógico. Se trabalharmos com a ideia de inovação mais do que com a de reforma -, veremos que o estudo sistemático da temática resultará em um documento que demonstre as sínteses construídas pela escola a respeito do que se propõe e de onde se pretende chegar.

Questionados sobre a relação entre os projetos pedagógicos das escolas e a implantação das escolas de tempo integral, quatro respondentes afirmaram que este se encontrava em processo de reformulação, e cinco, que ainda não fora alterado. Dado que as nove escolas analisadas não elaboraram previamente a proposta 
pedagógica, questiona-se em que medida essa forma de encaminhar a mudança pode ter gerado incertezas em questão de preparação, considerando-se a importância de que sejam antecipadamente estudadas para que atinjam resultados. Destaca-se que a formação continuada centrada na escola poderia ter, entre outras, a função de prepará-las para a reorganização de sua proposta frente à política de escola de tempo integral, em uma relação de processos complementares que contribuiria para menores índices de dificuldade.

Os dados da pesquisa permitem perceber uma mudança vertical que, nesse momento inicial, ainda parece contar com bastante incompreensão por parte das escolas envolvidas. Ao falar dos processos de reforma e inovação, Carbonell (2002) aponta paradoxos que os acompanham, dentre os quais destacamos a dificuldade natural de implantar o novo, mesmo tendo o velho como única referência, paradoxo certamente hoje vivido pelas escolas:

As reformas são lideradas e executadas por pessoas que têm de abrir novos horizontes e estratégias de futuro com visões e culturas educativas do passado, defendidas e até idealizadas, porque são as únicas que conhecem e que um dia lhes proporcionaram oportunidades de estudo de promoção. (CARBONELL, 2002, p.23)

A respeito da relevância da proposta, é necessário haver investimento na formação e no desenvolvimento das escolas para que trabalhem apenas como cumpridoras de determinações que não conhecem verdadeiramente.

\section{ESCOLA DE TEMPO INTEGRAL: REESTRUTURAÇÃO DO ESPAÇO- TEMPO E EQUIPES DE TRABALHO}

A escola de tempo integral tem como uma de suas principais características a ampliação do tempo-espaço, permitindo o desenvolvimento de atividades diferenciadas. As escolas de Ponta Grossa que implantaram o tempo integral sentiram a necessidade de algumas modificações na organização escolar a fim de desenvolver a proposta.

Investigando-as, observamos que as principais modificações realizadas ocorreram na reorganização dos espaços físicos (em geral, sem ampliação ou reforma) e na redistribuição das tarefas entre os educadores:
Algumas salas de aula foram adaptadas para o funcionamento, houve remanejamento de professores. (Diretor A)

[...] adequação dos espaços para atender os alunos nove horas diárias. Saguão virou refeitório e sala da zeladoria hoje é sala de educação infantil. O laboratório de informática também é sala de aula. (Diretor D)

Muitas!!! A organização dos horários e escalas é um ponto bem marcante. Tudo gira em torno de escalas (parque/ biblioteca / quadra/ refeitório/ etc.). Também o horário do almoço das crianças, (horário livre) é bem difícil de organizar, pois os professores regentes saem neste horário. (Diretor $\mathrm{G}$ )

Ao mesmo tempo, afirmam a existência de alterações na organização dos espaços e na distribuição de tarefas. Sete dos nove diretores apontaram que elas ainda parecem ter sido insuficientes:

Ainda não está a contento devido à falta de espaço físico e recursos humanos. (Diretor C)

Sim, temos problemas sempre, mas tínhamos quando não era tempo integral. A falta de funcionários acontece e temos que nos organizar. Os espaços organizamos e ainda precisamos melhorar e os materiais nunca são suficientes, sempre tem novidades que precisamos adquirir. (Diretor D)

Ainda faltam recursos humanos. A dinâmica de uma escola de tempo integral é totalmente diferente das demais escolas. Quanto aos recursos físicos e materiais penso que agora está tudo concorrendo para uma melhor organização dos trabalhos. (Diretor E)

É importante observar que o planejamento físico pouco depende das escolas, já que, em grande parte dos casos, exige investimento municipal. Questionamos, assim, se as alterações realizadas não se restringem ao nível da improvisação de espaços, pois aquele mesmo espaço que comportava um número pequeno de alunos agora comporta o dobro para que eles permanecem o dia todo no estabelecimento. Dessa forma, é quase inevitável não falarmos na ampliação do espaço escolar para que a escola seja um lugar em que a criança sinta prazer em permanecer, um lugar que estimule a aprendizagem e que não seja estressante para as pessoas que nele convivem.

Nacionalmente, não se encontra disponível um documento que normatize a organização estrutural das escolas para o funcionamento em tempo integral. É importante que o espaço ofereça condições para a 
formação do aluno em todas as suas dimensões, com espaços que permitam atividades diversificadas.

Partindo deste pressuposto, buscamos investigar quais são os espaços disponíveis nas escolas e identificamos que somente dois deles - pátio coberto e quadra - são comuns às nove instituições. Bibliotecas, salas de informática, laboratório de ciências, sala de professores e para hora-atividade são praticamente inexistentes na maioria das instituições. Também são apresentados outros espaços não comuns a todas as escolas, como sala de vídeo, horta, sala para atividades diversificadas e de expressão corporal.

Em relação às salas de aula, a grande maioria delas atende a média de 25 a 30 alunos, pois, das 74 classes, verificou-se que apenas sete ultrapassavam essa proporção. Classes muito cheias podem resultar em indisciplina e dificuldades de aprendizagem, sendo necessário não ultrapassar 25 alunos por turma, especialmente nos dois primeiros anos do Ensino Fundamental.

Ao falar sobre os espaços físicos e ambientes de trabalho nos processos de inovação, Carbonell lembra que estes, por si só, não garantem mudança efetiva:

A simples modernização da escola nada tem a ver com a inovação. Assim, encher as classes de computadores, realizar saídas ao entorno, cultivar uma horta ou realizar oficinas são frequentemente simples desenhos que enfeitam a paisagem escolar, mas que não modificam absolutamente as concepções sobre o ensino e a aprendizagem estabelecidas no mais rançoso conservadorismo. (CARBONELL, 2002, p.20)

Mais do que contar com espaços e recursos, é preciso desenvolver concepções acerca deles. Assim, vemos reforçada a importância dos processos de formação de professores, pois é por meios deles e da análise das dificuldades que as concepções podem se construir. Sem desenvolvimento institucional e com falta das condições materiais necessárias, as mudanças podem, de fato, ser limitadas.

A alteração organizacional da escola também trouxe mudanças no trabalho de diretores, pedagogos e de professores. Em relação ao trabalho dos professores, observou-se que a grande maioria possui 40 horas semanais de trabalho na mesma escola, ou seja, dos 141 professores envolvidos, 91 trabalham exclusivamente em uma escola.
Em decorrência disso, a pesquisa revelou melhorias em termos de hora-atividade, mas apontou a de diversificação de tarefas:

Os professores de 40 horas tiveram que assumir projetos em contraturno. O horário de almoço passou de 1 hora e meia para uma hora. (Diretor B)

Num período trabalham conteúdo e no outro projetos. (Diretor C)

Os professores de 40 horas têm uma turma onde são regentes do $1^{\circ}$ ou $2^{\circ}$ ciclo e, no período contrário, desenvolvem projetos. Facilita no cumprimento dos $33 \%$ da hora-atividade e os professores de 20 horas desenvolvem projetos, dificulta para fechar horários e hora-atividade. (Diretor D)

A ETI precisa favorecer a qualidade de trabalho tanto dos alunos quanto dos professores. Percebeu-se grande melhoria principalmente em relação às horas de planejamento que aconteciam nas sextas-feiras no período da tarde, para o que as crianças são dispensadas antes. Nos outros dias da semana, os professores também dispunham de 13\% de horas de trabalho voltadas a planejamento, avaliação e formação.

Contudo, questionamos em que medida se revela produtiva - seja para professores, seja para aluno - a permanência de um mesmo docente desenvolvendo, com sua própria classe, tanto atividades curriculares do núcleo comum como das áreas diversificadas. Fato é que a condição profissional do professor melhorou muito, principalmente no que se relaciona às suas horas de planejamento, as quais passaram a ser mais valorizadas no âmbito da organização escolar.

Quanto ao diretor e pedagogo, dado o caráter de coordenação que exercem na instituição, vimos que houve um aumento de demandas e, consequentemente, de dificuldades:

A demanda de aluno aumentou e é necessário que fiquemos com as crianças na hora do almoço. (Diretor A)

Sim, pois é novo e tudo o que é novo traz uma certa inquietação, mas, estudando, dá certo. (Diretor C)

Totalmente. Hoje passamos mais tempo com o aluno, mas são muitos e o trabalho, as atividades os projetos, acompanhamento pedagógico, verbas, aplicação, prestação de contas, atendimento à comunidade escolar dobraram também. (Diretor D)

A atividade dos gestores é muito complexa e carregada de tarefas. Para que este cargo não seja 
exaustivo e penoso, a tomada de decisões precisa ser feita por meio de uma gestão democrática que conte com a participação de todos os setores da escola em um processo de coparticipação e colaboração.

As atribuições de diretores e pedagogos parecem ter aumentado principalmente em decorrência da nova organização posta, pois as falas dos pesquisados indicaram as dificuldades surgidas do novo tempo de intervalo de almoço (antes inexistente na escola de tempo parcial) e a maior incidência de questões relativas ao relacionamento entre alunos.

Somados aos dados anteriormente mostrados, relativos às condições de estrutura física e adequação das equipes, podemos inferir que a proposta de tempo integral pode ser geradora de uma sobrecarga de trabalho para as equipes de gestão que passam, inclusive, a assumir responsabilidades que ultrapassam aquelas para as quais são designados, como o cuidado com alunos nos tempos de intervalo.

\section{O TEMPO INTEGRAL E AS PRÁTICAS PEDAGÓGICAS FACE À EDUCAÇÃO INTEGRAL}

O elemento configurador de uma escola de tempo integral é a oferta de atividades diversificadas. Essas atividades comporão o currículo, embora não objetivem substituir as atividades curriculares das áreas de conhecimento tidas como núcleo comum, configurando-se complementares. Elas podem abordar outras áreas de conhecimento, como linguagens, artes, expressão corporal, ludicidade, sustentabilidade e meio ambiente.

Nas ETI do município pesquisado, as atividades diferenciadas que complementavam o currículo comum eram divididas em seis eixos norteadores da organização pedagógica do tempo escolar, são eles: ludicidade; corpo e movimento; acompanhamento pedagógico; homem, meio ambiente e sustentabilidade; cidadania e diversidade cultural; e linguagens. Em cada eixo, contemplava-se uma diversidade de atividades propostas conforme demonstrado na tabela a seguir.

Tabela 1 - Eixo, atividade e organização pedagógica

\begin{tabular}{|c|c|c|c|c|c|}
\hline \multicolumn{6}{|c|}{ EIXOS NORTEADORES DA ORGANIZAÇÃO PEDAGÓGICA } \\
\hline 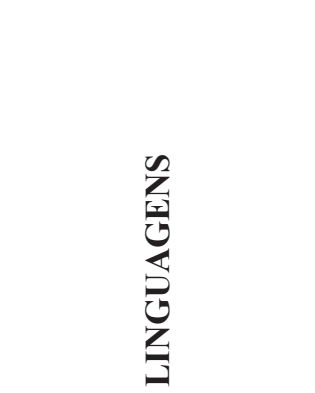 & 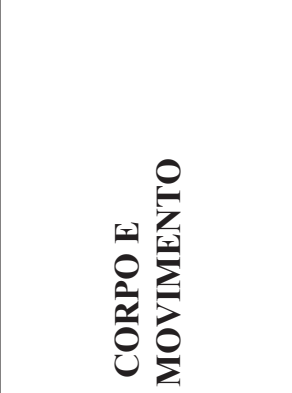 & 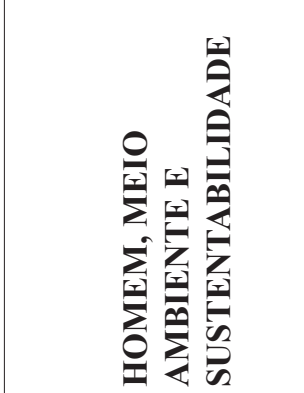 & 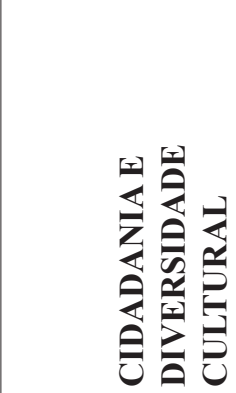 & $\frac{\sqrt{2}}{2}$ & 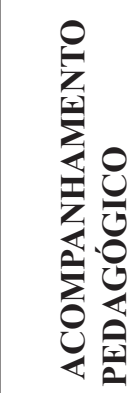 \\
\hline $\begin{array}{l}\text { Leitura } \\
(\mathrm{E}, \mathrm{H})\end{array}$ & $\begin{array}{l}\text { Danças } \\
(\mathrm{A}, \mathrm{G})\end{array}$ & Sustentabilidade $(\mathrm{E})$ & Valores $(\mathrm{G})$ & $\begin{array}{l}\text { Música } \\
(\mathrm{A}, \mathrm{D}, \mathrm{E}, \mathrm{H}, \mathrm{G})\end{array}$ & $\begin{array}{l}\text { Tarefa } \\
(\mathrm{A}, \mathrm{I})\end{array}$ \\
\hline $\begin{array}{l}\text { Contação de história } \\
\text { (G) }\end{array}$ & $\begin{array}{l}\text { Educação Física } \\
(\mathrm{A}, \mathrm{B})\end{array}$ & Meio ambiente $(\mathrm{E})$ & Cidadania $(\mathrm{E})$ & Brincadeiras (B) & \\
\hline $\begin{array}{l}\text { Inglês } \\
(\mathrm{G})\end{array}$ & $\begin{array}{l}\text { Corpo e } \\
\text { Movimento (B) }\end{array}$ & $\begin{array}{l}\text { Horta } \\
(\mathrm{G}, \mathrm{I})\end{array}$ & & & \\
\hline $\begin{array}{l}\text { Português/ Jogos de } \\
\text { Português } \\
(\mathrm{H}, \mathrm{I})\end{array}$ & $\begin{array}{l}\text { Expressão corporal } \\
(\mathrm{E})\end{array}$ & & & & \\
\hline $\begin{array}{l}\text { Matemática/ Jogos de } \\
\text { Matemática } \\
(\mathrm{E}, \mathrm{H}, \mathrm{I})\end{array}$ & $\begin{array}{l}\text { Esportes } \\
\text { (I) }\end{array}$ & & & & \\
\hline $\begin{array}{l}\text { Teatro } \\
(\mathrm{G}, \mathrm{I})\end{array}$ & $\begin{array}{l}\text { Futebol e atletismo } \\
(\mathrm{G})\end{array}$ & & & & \\
\hline $\begin{array}{l}\text { Artes } \\
\text { (I) }\end{array}$ & $\begin{array}{l}\text { Xadrez } \\
(\mathrm{E}, \mathrm{H}, \mathrm{G})\end{array}$ & & & & \\
\hline $\begin{array}{l}\text { Informática } \\
\text { (H) }\end{array}$ & & & & & \\
\hline
\end{tabular}


A organização para a participação do aluno nas atividades dos eixos de diversificação foi feita de três formas diferentes. Na maioria das escolas (7), os alunos eram organizados por turma (a mesma classe em que estão matriculados); em uma, mesclaram-se alunos de diferentes anos (faixa etárias) e turmas (classes); e, na última (1), os alunos foram organizados por seu ano de matrícula, sem a necessária vinculação com sua classe, ocorrendo uma mesclagem de turmas que gerou o agrupamento de crianças da mesma faixa etária, mas de diferentes classes do mesmo ano.

Durante a semana, os alunos participaram, em média, de duas ou três atividades diferentes por dia. Apenas em uma das nove escolas o aluno permaneceu somente em uma atividade por dia. A pesquisa também revelou que a designação das atividades a serem desenvolvidas foi uma escolha da escola e não do aluno, o que certamente restringe sua autonomia na busca das dimensões que lhe sejam mais caras, processo fundamental numa proposta de ETI.

Novamente, vimos reforçada a hipótese da pouca compreensão do sentido da educação integral entre as escolas, pois o princípio da socialização não se desenvolve somente com alunos da mesma faixa etária, mas com a convivência e o trabalho entre crianças de diferentes faixas etárias e níveis de aprendizagem. Sobre a importância de que toda atividade desenvolvida no espaço escolar seja considerada uma atividade educativa que socialize e ensine por meio das diferenças, Antunes e Padilha asseveram:

Queremos separar o currículo monocultural e, pior ainda, daltônico culturalmente, que não enxerga as diferentes diferenças e as múltiplas semelhanças entre os sujeitos do processo educativo, em várias dimensões - culturais, sociais, econômicas, políticas, entre outras. (2010, p. 99)

Dessa forma, é importante que toda escola aproveite e explore o conjunto de atividades desenvolvidas e de experiências propiciadas, ensinando em situações diferenciadas. Decorre daí, também, a percepção do sentido educativo de outros momentos, como o da higiene e da alimentação. Em relação a esses, diretores pesquisados apontaram sua dinâmica na proposta de ETI:

Falta um "escovódromo" mas será contemplado na reforma prevista. (Diretor A)
Encontramos dificuldades na hora da escovação pois o número de lavatórios é insuficiente, temos que levar turma por turma, e essa higiene demora a manhã e a tarde toda. (Diretor B)

Existe incidência de pediculose, problema de pele devido à falta de higiene, bicho de pé, etc... (Diretor C)

Os alunos utilizam os sanitários acompanhados pelas professoras. Antes das refeições para utilização dos sanitários e higienização das mãos e após as refeições para escovação. Uma vez na semana é feito flúor. Esse horário é complicado, gera tumulto no saguão e atrapalha as turmas, precisamos reorganizar. (Diretor D)

Não é um momento muito tranquilo devido ao grande número de alunos e também, quando realizam a higiene com outros professores que não o seu, se agitam muito. (Diretor E)

Poucos bebedouros e pia para escovação. (Diretor F) É feito de acordo com a necessidade. (Diretor $\mathrm{H}$ ) Como a criança fica mais tempo na escola, têm pessoas preocupadas e ajudando-as na higiene. A falta de banheiros é uma grande dificuldade. (Diretor I)

Em alguns casos, as atividades de higiene configuraram-se situações exaustivas para a escola devido à falta de espaço e ao acúmulo de crianças em tais momentos. Seria importante que pudessem contar com orientação pedagógica específica para a atividade, a fim de que esta assumisse sua dimensão efetivamente educativa.

Procuramos investigar também a alimentação das crianças enquanto permaneciam na escola:

É ótima a aceitação. Alimentação completa e saudável, supervisionada por nutricionistas da SME. (Diretor A)

A alimentação é maravilhosa, bem variada e saudável, os alunos se alimentam muito bem, nunca falta lanche, alimentos e frutas. (Diretor B)

Estão se adaptando, mas, a maioria se alimenta bem. (Diretor C)

Ótima, aceitam bem, os pais estão satisfeitos com as mudanças nos hábitos alimentares dos filhos que hoje comem fruta, verdura, legumes, hortaliças e cereais. (Diretor D)

É uma cardápio variado. As crianças recebem o arroz, feijão, carne, pão, frutas e verduras todos os dias. A quantidade segue orientação das nutricionistas. Quanto à aceitação, é muito bem aceita pelas crianças, com raras exceções. (Diretor E) 
Ótima aceitação e excelente qualidade, quantidade e variedade adequados. (Diretor F)

No início foi bem difícil, hoje já não vemos esta dificuldade, visto que temos trabalhos em sala projetos sobre alimentação. (Diretor $\mathrm{G}$ )

É feita de acordo com o número de alunos atendidos e a suficiente e com boa aceitação. (Diretor $\mathrm{H}$ )

Os alunos gostam da alimentação e se alimentam bem. (Diretor I)

Embora destacada pelos diretores prioritariamente em seu sentido de cuidado, a alimentação na escola de tempo integral se revela como um dos ganhos centrais que certamente incidirá em melhoria da condição de saúde das crianças e, em um ciclo contínuo, em melhoria da aprendizagem. Fundamental na proposta da ETI é que todas as condições diferenciadas se voltem para o foco da educação integral, potencializando não apenas o cuidado, mas essencialmente a qualidade das aprendizagens.

Em relação a possíveis influências da nova proposta sobre o desenvolvimento das crianças, os diretores investigados se posicionaram do seguinte modo:

Houve mais aprendizagem. (Diretor C)

Sim, hoje os alunos aprendem com a qualidade e gostam de estar na escola. (Diretor D)

Sem dúvida percebemos avanços na aprendizagem dos alunos. (Diretor G)

Sim, pois com maior número de horas na escola facilita a aprendizagem. (Diretor $\mathrm{H}$ )

Percebemos que os alunos progrediram em suas aprendizagens e desenvolvimento. (Diretor I)

Sim. Pelo fato do aluno ter mais tempo para estudar e também participar das aulas de apoio estão apresentando bons resultados, porém, ainda temos alunos com muitas dificuldades para aprender, apesar do trabalho desenvolvido. (Diretor E)

Percebemos que, para a maior parte das escolas (6 de 9), o tempo integral e as mudanças no trabalho pedagógico parecem ter contribuído com a aprendizagem das crianças, sendo o "tempo" e as ações nele efetivas - diversificação e maior apoio - elementos centrais. Para uma das escolas, o cuidado é o fator contributivo da ETI, e outras duas instituições ainda não identificam avanços, pois as dificuldades de aprendizagem persistiram.

Um elemento importante a ser desencadeado pelas escolas para seu autoconhecimento em relação ao trabalho desenvolvido no âmbito da proposta de tempo integral seria a avaliação, a qual permitiria que as escolas refletissem sobre o modo pelo qual como a política está sendo desenvolvida.

Dificuldades são etapas naturais em qualquer processo e, certamente, se intensificam nas concepções, práticas e organizações subjacentes à escola de tempo integral. Importante é a convicção de que a política de tempo integral é uma alternativa pedagógica importante frente aos muitos problemas da educação brasileira.

\section{CONSIDERAÇÕES FINAIS}

No leque das possibilidades que se colocam para a oferta de uma escola de qualidade encontra-se a proposta da escola de tempo integral. E é no âmbito desse movimento que se encontra a proposta de escola em tempo integral da cidade investigada.

A pesquisa demonstrou que a iniciativa partiu essencialmente da secretaria de educação como proposta posta às escolas. Ainda que tenha havido formação para preparar gestores e escolas para a nova experiência, esta parece ter assumido um caráter mais pontual e pouco contínuo, dificuldade que, somada ao fato de que a proposta foi recebida de fora, contribuiu para certa incompreensão da proposta por parte daqueles que estão envolvidos dentro da escola.

Este movimento que podemos chamar de reforma acabou gerando diversas consequências. Um ponto observado foi o de que a concepção de escola de tempo integral existente entre os diretores está mais associada ao benefício do cuidado para com os alunos, sugerindo uma visão assistencialista. Há, entre eles, pouca clareza quanto ao sentido da educação integral.

Em decorrência, identificaram-se formas pouco diversificadas de organizar o trabalho em torno dos projetos. Outro aspecto percebido diz respeito à estrutura física e organizacional para o trabalho em tempo integral, pois verificou-se ausência de espaços como biblioteca, sala de informática, refeitório e sala de ciências. Ao mesmo tempo em que grande parte dos professores teve sua carga-horária de hora atividade garantida (ponto positivo a ser destacado), espaços para estudo e planejamento foram improvisados ou são inexistentes; apenas quatro escolas contam com essa possibilidade. 
O Brasil convive com um atraso na educação integral e na escola de tempo integral. Todavia, sua oferta precisa se fazer como uma política pública para todos - voltada ao que pode ser considerado um direito de cidadania capaz de atender às necessidades de pais trabalhadores, ao direito que as crianças tem à cultura e à proteção social. Trata-se, nas palavras de Gadotti (2009), de uma educação integral, integrada e integradora que configura um projeto pedagógico de escola capaz de aproximar os saberes culturais das famílias, do bairro e de toda a municipalidade.

É preciso fortalecer a formação dos professores para que de fato compreendam a política, desenvolvendo-a e implementando-a para uma educação realmente integral.

\section{REFERÊNCIAS}

ANTUNES, A.; PADILHA, P. R. Educação cidadã, educação integral: fundamentos e práticas. São Paulo: Instituto Paulo Freire, 2010.

ARroyo, M. G. O direito ao tempo de escola. Caderno de Pesquisa, São Paulo, n. 65, maio. 1988, p. 3 - 10.

BRANCO, V. Desafios para a implantação da educação integral: análise das experiências desenvolvidas na região sul do Brasil. Educar em Revista, Curitiba, n. 45, jul./set. 2012, p.111-123.

BUENO, J. A. R. Educação pública e desenvolvimento: um estudo sobre o Ensino Fundamental público no município de Ponta Grossa/PR. 2017, 170f. Dissertação (Mestrado em Ciências Sociais Aplicadas) - Universidade Estadual de Ponta Grossa, Ponta Grossa, 2017.

CARBONELL, J. A aventura de inovar: a mudança na escola. Porto Alegre: Artmed, 2002.

CAVALIERE, A. M. Tempo de escola e qualidade na educação pública. Educação e Sociedade, Campinas, v. 28, n.100, out. 2007, p. 1015-1035.

CAVALIERE, A. M. Escola pública de tempo integral no Brasil: filantropia ou política de Estado? Educação e Sociedade, Campinas, v. 35, n. 129, out./dez. 2014, p. 12051222.

COELHO, L. M. CAVALIERE, A. M. Educação brasileira e(m) tempo integral. Petrópolis: Vozes, 2002.

GADOTTI, M. Educação integral no Brasil: inovações em processo. São Paulo: Editora e Livraria Instituto Paulo Freire, 2009.

LEITE, L. H. A. Educação Integral, territórios educativos e cidadania: aprendendo com as experiências de ampliação da jornada escolar em Belo Horizonte e Santarém. Educar em Revista, Curitiba, n. 45, jul./set. 2012, p. 57-72.

MAURÍCIO, L. V. Escritos, representações e pressupostos da escola pública de horário integral. In: MAURICIO, L. V. Em Aberto, n. 80. Brasília: INEP, 2009, p. 15-31.

MOLL, J. et. al. Caminhos da educação integral no Brasil: direito a outros tempos e espaços educativos. Porto Alegre: Penso, 2012. 